\title{
The Role of Perceived Effectiveness of Policy Measures in Predicting Recycling Behaviour in Hong Kong
}

\begin{abstract}
Hong Kong is a compact and 'land-hungry' city where recycling has become an important measure for treating waste and reducing the demand on the limited landfills. The objectives of this paper are to extend the model of recycling attitude and behaviour to explain the relationship between perceived policy effectiveness and recycling behaviour. Previous studies on recycling attitude and behaviour had widely adopted the Theory of Planned Behaviour (TPB) and the Norm Activation Model (NAM), and drawn policy implications from them. Nevertheless, little research has been conducted to investigate the role of perceived effectiveness of policy measures in predicting recycling behaviour. To address this, a model that integrates the TPB and NAM was proposed in this study, and a street survey was conducted to investigate the case. The results illustrate that recycling intention is influenced by subjective norms, perceived behavioural control, moral norms, and awareness of consequences, as well as a newly proposed construct, namely perceived policy effectiveness. The study proved self-reported recycling behaviour (direct behaviour) and support for policy measures (indirect behaviour) are influenced by recycling intention. All in all the Government should provide more recycling bins, guidelines on recycling activities, and should accent what it has been doing to facilitate and encourage recycling.
\end{abstract}

Keywords: recycling; attitude; theory of planned behaviour; policy; Hong Kong

\section{Introduction}

Waste reduction and recycling are very important elements of the waste management framework in Hong Kong, as well as around the world. They help conserve natural resources and reduce demands for valuable landfill space (Environmental Protection Department, 2010). The Hong Kong Government introduced a campaign in 2005 to enhance the awareness of the importance of recycling. As parts of the campaign, it set up waste-separation facilities and took other action to facilitate recycling, such as running a website to provide the necessary information. The Government has provided around 16,000 sets of waste separation bins in public areas such as roadsides, parks, sports venues, etc. (Information Services Department, 2013). As of 2010 , around 1,500 housing estates representing about $74 \%$ of the local population have joined a domestic waste programme conducted by the Government to provide waste separation facilities (Information Services Department, 2010). However, local environmental groups have voiced the criticism that the waste separation bins were still 
insufficient and not conveniently located (Sing Tao Daily, 2013).

Despite a slight decline in domestic waste disposal rates since the Government's efforts to reduce waste began (Chung, 2010), Hong Kong's three major landfills are predicted to reach their full capacity in the $21^{\text {st }}$ century. According to government statistics, the annual growth of municipal solid waste from 1996 to 2004 was 3\%, while the annual population growth was just $0.9 \%$. Over the past three decades, daily municipal solid waste per capita in Hong Kong increased from $0.97 \mathrm{~kg}$ to $1.27 \mathrm{~kg}$. This implies that each person in Hong Kong had produced $30 \%$ more waste than before, posing a heavier burden on landfills (Environment Bureau, 2013). To cope with the enormous growth of municipal solid waste, the Government proposed an expansion of the current three landfills from 270 to 550 hectares because they would reach their full capacities by the end of the 2010s. Both environmental groups and local residents criticised the idea because of the potential environmental impacts (Legislative Council, 2013). The expansion of one of the three landfills was eventually shelved by the Government due to strong social opposition. Lawmakers passed a motion to adjourn the debates on funding to enlarge the other two landfills.

In May 2013, a blueprint for the sustainable use of resources in the coming decade was published by the Government (Environment Bureau, 2013). It listed a few facts about Hong Kong:

- Hong Kong holds the highest daily domestic waste generation rate per capita among other Asian cities (including Taipei, Seoul, and Tokyo).

- The current public spending on waste collection, transfer, treatment, and landfilling is HKD 1.4 billion per year.

- $52 \%$ of the municipal solid waste is disposed of in landfills.

The Government also targeted to reduce the landfilling rate from $52 \%$ to $22 \%$ in ten years' time by adopting incineration and increasing recycling, and it has recognised the importance of public participation in related campaigns (Environment Bureau, 2013). So apart from setting up recycling facilities, it has committed itself to recycling by providing more public education.

Policy makers should understand the association between policy measures and the behaviours of the general public to further improve public policies and address public demands. An understanding of public perception of policy effectiveness and its impact on behavioural intentions could shed light on policy formulation. Previous research efforts have studied the causes that influence recycling behaviour (e.g., Oom Do Valle et al., 2005; Sidique et al., 
2010; Tonglet et al., 2004). The authors attempted to include additional factors to improve the models' predictive power. Although these studies also described policy implications for changing factors that influenced recycling behaviour, little research has been done on the impact of perceived effectiveness of various policy instruments in relation to encouraging recycling intentions. Wan and Shen (2013) proposed the relevance of perceived policy effectiveness in predicting recycling behaviour, however the idea was not empirically tested. Little is known about the inclusion of this factor into the TPB and NAM as a predictor of recycling intentions. The objectives of this paper are to extend the model of recycling attitude and behaviour and to explain the role of perceived policy effectiveness in predicting recycling behaviour.

\section{Literature Review and Conceptual Framework}

\subsection{The Theory of Planned Behaviour (TPB)}

The theory of reasoned action (TRA; Ajzen and Fishbein, 1980) suggested that an individual's intention to perform a certain behaviour is influenced by attitude and subjective norms. Attitude toward behaviour refers to the function of an individual's beliefs toward, and a subjective evaluation of, that behaviour (Fishbein and Ajzen, 1975). Subjective norms or social pressure are a function of the perceived expectations by other individuals or groups who are important or close to a person (such as friends, peers, neighbours, etc.), and that person's motivation to comply with these expectations (Fishbein and Ajzen, 1975). The TRA assumes that an individual's behaviour is under volitional control (Tonglet et al., 2004); however, Liska (1984) argued that performing a behaviour may be facilitated or interfered with by other factors, e.g. lack of knowledge, skills, opportunities, etc. The Theory of Planned Behaviour (TPB; Ajzen, 1991) is extended from the TRA by including an additional variable, perceived behavioural control (PBC). $\mathrm{PBC}$ refers to an individual's perception of his or her ability to perform certain behaviours (Ajzen, 1991). Oom Do Valle et al. (2005) identified two key dimensions of PBC that include external and internal conditions. The external conditions are the ease and convenience of performing a behaviour and the internal

conditions are an individual's perceived own abilities including his or her own understanding and knowledge of the behaviour.

Ajzen (1991) proposed that the TPB is a general theory that can be applied in explaining all kinds of social behaviours. The TPB has received considerable attention in the literature and its efficacy in explaining behaviour has been proved (Armitage and Conner, 2001). The TPB has been widely adopted in attitude-behaviour studies, for instance, in the area of technology acceptance (Mathieson, 1991), the dishonest actions of college students (Beck and Ajzen, 
1991), smoking (Godin et al., 1992), driving violations (Parker et al., 1992), and the use of public transportation (Heath and Gifford, 2002). Heath and Gifford (2002) described the TPB as a 'parsimonious' theoretical framework that includes major predictors with precise operational definitions of each construct. Tonglet et al. (2004) suggested that the TPB is a systematic framework for identifying predictors of behavioural choices. It has also served as the foundation of studies on recycling behaviour. The TPB proposes that behavioural intention, the antecedents of behaviour, are predicted by attitude, subjective norms, and perceived behavioural control (PBC). Generally, an individual with a more positive attitude, stronger subjective norms, or a higher level of $\mathrm{PBC}$ toward a behaviour would register enhanced levels of behavioural intentions. The TPB has been successfully applied in the study of recycling behaviour (e.g., Chen and Tung, 2010, Oom Do Valle et al., 2005; Tonglet et al., 2004).

The following hypotheses are proposed based on the TPB.

Hypothesis 1 (H1): Attitude relates positively to recycling intention.

Hypothesis 2 (H2): Subjective Norms relate positively to recycling intention.

Hypothesis 3 (H3): Perceived Behavioural Control relates positively to recycling intention.

\subsection{The Norm Activation Model of Altruistic Behaviour (NAM)}

The Norm Activation Model of Altruistic Behaviour (NAM) was originally developed for application in the field of pro-social behaviour (Schwartz, 1977). The NAM proposed that behaviour is explained by four key factors: personal norms, social norms, awareness of consequences, and ascription of responsibility. A personal norm can simply be interpreted as the rule that governs an individual in considering if a behaviour is the right thing to do; this is conceptualised as feelings of moral obligation. The impact of social norm influences on individual behaviour is mediated by the personal norms of altruistic behaviour. This relationship was confirmed by the results of Hopper and Nielsen's (1991) and Bratt's (1999) studies on recycling behaviour. In addition, the NAM elaborated that the correlation between personal norms and behaviour is moderated by the awareness of consequences and the ascription of responsibility. Therefore, the relationship between personal norms and behaviour will be stronger if individuals are aware of the consequences, and feel a certain level of responsibility for those consequences.

In a review of the NAM, Thøgersen (1996) suggested that pro-environmental behaviour, unlike the TPB, is not simply based on an individual's cost and benefits analysis, but on a person's moral beliefs. Thøgersen (1996) further suggested that the NAM would offer a more appropriate and reasonable basis for studies on recycling behaviour. Davies et al. (2002) 
highlighted the importance of the norm internalization process in understanding recycling behaviour. If an individual performs a new behaviour, social norms would direct an individual's decision to act. The social norms will be internalised and will become personal norms if the behaviour becomes recurrent. Therefore, in performing recycling behaviour, individuals may first be influenced by social norms and subsequently by personal norms. The NAM has been adopted in research on pro-environmental behaviour involving moral considerations (e.g. Hopper and Nielsen, 1991; Stern et al., 1985; Vining and Ebreo, 1992). These studies suggested that pro-environmental behaviour, including recycling, could be conceptualised as a type of altruistic behaviour. Although the TPB and NAM explain behaviour in different perspectives, attempt could be made to integrate the two models.

\subsection{Integrating the TPB and NAM}

Oom Do Valle et al. (2005) suggested that people tend to observe and learn from others in society before determining their actions. In the TPB, subjective norms represent pressure and influence from the opinion of the referent (such as peers, family members, and neighbours); the norms have a positive effect on behavioural intention. In the NAM, social norms refer to the values and attitudes of referents that are commonly agreed upon in a society (Hopper and Nielsen, 1991). The subjective norms and social norms in the TPB and NAM are conceptualised in a similar manner. This premise was included in $\mathrm{H} 2$ above.

Ajzen (1991) suggested that the TPB allows the flexibility of adding variables, which can contribute significantly to explaining certain behaviours. Most studies on recycling that have applied the TPB proposed the addition of variables for improving the predictive power of their respective models. Tonglet et al. (2004) and Chen and Tung (2010) included a moral norm in their studies on recycling behaviour. This norm refers to an individual's concerns about ethical and social responsibility in performing a certain behaviour. The conceptualization of a moral norm is similar to that of the personal norm in the NAM. Moral norms have been included and represented in the attitudes of individuals (Kaiser and Scheuthle, 2003). However, Harland et al. (1999) found that moral norms increase variance by $1 \%$ to $10 \%$ when explaining behavioural intentions in different contexts. Chen and Tung (2010) further recognised that moral norms are involved and statistically significant in predicting behavioural intentions. Examples of other studies include those pertaining to dishonest actions (Beck and Ajzen, 1991) and driving violations (Parker et al., 1992). Measuring constructs of moral norms from attitudes enhances the level of conceptual preciseness. In this study, attitudes focus on the feelings of individuals; and moral norms emphasize the perceived moral obligation of recycling. 
Thus, the following hypothesis is proposed.

Hypothesis 4 (H4): Moral norms relate positively to recycling intention.

Although the awareness of consequences is considered to be one of the variables used to activate the relationship between personal norms and behaviour in the NAM, Davies et al. (2002) explained that a higher awareness level of desirable outcomes of certain behaviour would increase the intention to perform recycling. This factor was proved to be significant and a direct predictor of recycling behaviour (Tonglet et al., 2004; Chen and Tung, 2010) when applying the TPB. Bamberg and Schmidt (2003) stressed that the TPB assumes the individual to be a "utility-maximizing actor" (p.267), and that he or she would select an alternative with the most positive behavioural consequences. Ajzen (1991) measured attitudes in terms of an individual's beliefs in the behaviors' outcomes by his or her evaluation of those outcomes. Therefore, attitudes in the TPB are related to the awareness of consequences. A number of studies (e.g. Tonglet et al., 2004; Chen and Tung, 2010; Wan et al., 2012) have considered awareness of consequences as a construct. Attitudes in these studies are operationalised as individuals' feelings about recycling (e.g. good, useful, rewarding, etc.), while awareness of consequences emphasizes the individual's knowledge of the consequences of recycling behaviour.

Therefore, the following hypothesis is proposed.

Hypothesis 5 (H5): Awareness of consequences relates positively to recycling intention.

The TPB suggests that an individual's intention to perform a certain behaviour is the immediate determinant of that specific behaviour. Tobler et al. (2012) summarised in their study on climate change that behaviours are distinguished between different manners:

- Indirect Behaviour - including supporting government policies or voting for favourable politicians. It is operationalised as the support for current and proposed policy measures;

- Direct Behaviour - including performing pro-environmental action. It is operationalised as self-reported past behaviour.

The following hypotheses are formulated.

Hypothesis 6 (H6): Recycling intention relates positively to direct recycling behaviour.

Hypothesis 7 (H7): Recycling intention relates positively to indirect recycling behaviour

\subsection{The Research Gap: Perceived Effectiveness of Policy Measures}

The policy measures or tools in related areas have been analysed and researched in the literature. A well-known approach is "carrots, sticks, and sermons" (Vedung, 1998), and it can 
be analogous to "incentive, regulation, and education," respectively, with which a government may implement measures to motivate or change people's mindset and behaviour (Hood, 2006).

Elmore (1987) categorised government policy tools into four different types: mandates, inducements, capacity-building, and system-changing. Similarly, Gormley (1987) categorised policy tools into three types of policy instruments: coercive, catalytic, and hortatory tools. Schneider and Ingram (1990) suggested that policy measures serve as motivational devices to change people's behaviour.

Concerning recycling attitude and behaviour, the perceived effectiveness of policy instruments is expected to correlate with behavioural intentions. In a review of pro-environmental behaviour by Steg and Vlek (2009), perceived effectiveness and acceptability of policy measures were examined in terms of transport (e.g. Jakobsson et al., 2000) and energy (e.g. Steg et al., 2005). These studies emphasised the determinants influencing the acceptability of policy measures, such as Value-Belief-Norm theory (Steg et al., 2005), incentives versus disincentives (Steg et al., 2006), and demographic and attitudinal factors (Tobler, 2012).

Despite the fact that the TPB had been proved as a robust model in explaining pro-environmental behaviour, previous studies have described policy implications for change factors influencing recycling behaviour. The discussion of policy measures stressed how to change attitudes, address social norms, and facilitate pro-environmental behaviour (Steg and Vlek, 2009). Although prior studies have been carried out to investigate how policy measures affect people's behaviour, there was little research into how perceived effectiveness of policy measures motivates people to perform certain behaviour. Steg et al. $(2006 ; 2009)$ argued whether an effective policy can measure an increase in the attractiveness of a pro-environmental behaviour. Wan and Shen (2013) proposed in an editorial that if a motivational device built by the government is perceived as more effective, a higher level of intention would be induced to perform that particular behaviour.

The perceived policy effectiveness of a measure refers to an individual's favourable or unfavourable perception of a specific policy measure. This study proposed to operationalise it by asking respondents about their feelings on what the public authority provides in terms of effectiveness, clarity, and adequacy (e.g. sufficiency of waste separation bins, clarity of guidelines and promotion, etc.). The policy measure items are suggested to be drawn upon the policy framework of the local authority where the respondents reside. This would enhance the relevance of the measurement items and subsequently the validity of the results. 
Finally, the following hypothesis is proposed.

Hypothesis 8 (H8): Perceived policy effectiveness relates positively to recycling behaviour.

Drawing upon the aforementioned literature, a conceptual framework is formulated as shown in Figure 1.

$<<$ Figure 1 here $>>$

\section{Questionnaire Design and Data Collection}

The questionnaire used in the street survey for the current study was designed based on recycling literature and the TPB theoretical framework (Ajzen, 1991; Tonglet et al., 2004; Sidique et al., 2010). It included:

- Indicators for the two newly proposed constructs, i.e. perceived policy effectiveness and indirect behaviour, which were based on the current and proposed policy measures in Hong Kong (e.g. plastic bag levy, solid waste charging, etc.) (Environmental Protection Department, 2005, 2010) (See Appendix A);

- A seven-point Likert scale that was used to measure the components of the TPB, with 7 indicating a positive view and 1 a negative view;

- Items for the six major independent variables: attitude, subjective norms, PBC, moral norms, awareness of consequences, and perceived effectiveness of government policy;

- Questions regarding the dependent variables of recycling intention, direct, and indirect behaviour; and

- Questions that solicit demographic information (such as age, gender, education level, monthly income, and household size).

To enhance internal validity, a pilot test was organised in which twenty copies of the questionnaire were randomly distributed to respondents. Some wording in the questionnaire was then refined according to the test results. This version became the final one.

The survey covered three major regions in Hong Kong; it was conducted in:

- Four shopping malls that were selected according to a study on shopping malls' tenant mixes by Yiu and $\mathrm{Xu}$ (2012). They were considered easily accessible by public transportation; and

- Two railway stations - one is located in a residential area with the highest population in Hong Kong (Census and Statistics Department, 2011), while the other is one of the busiest stations (Information Services Department, 2012) in a commercial area. 
A total of 198 survey responses were collected. Profile details of the respondents and the corresponding population profile are presented in Table 1. The sample profile in this study is generally similar to the population profile in Hong Kong in terms of gender, education level, monthly income, and household size (Census and Statistics Department, 2011); the only exception is the overrepresentation of the young age groups in the sample.

$<<$ Table 1 here $>>$

\section{Data Analysis}

Structural Equation Modelling (SEM) is a method used to measure latent, unobserved concepts based on multiple observed indicators (Chin, 1998b; Jöreskog, 1989). Partial Least Squares (PLS) is a commonly used statistical approach to SEM, and it can be used to confirm the validity of constructs of an instrument and assess the structural relationships among those constructs (Chin, 1998a; Gefen et al., 2000). PLS, compared with covariance-based structural equation modelling, is more suitable for theory development as it requires a less stringent adherence to distributional assumptions (Jöreskog and Wold, 1982).

The current study used PLS because its premises were less limiting, and the sample size was relatively small. The statistical software application "SmartPLS 2.0" (Ringle et al., 2005) for PLS-based path modelling was applied to measure the causal model.

\subsection{Measurement Model}

The PLS measurement model was evaluated by examining the convergent and discriminant validity of indicators, as well as the composite reliability of indicators. The convergent validity tested the relationships among indicators within the same construct by examining the factor loadings and construct scores computed in the PLS model.

The measurement scales were evaluated based on the following criteria (Fornell and Larcker, 1981; Chin, 1998b):

(1) All indicator factor loadings should be significant and exceed 0.5.

(2) Composite reliability should exceed 0.7.

(3) Average variance extracted (AVE) by each construct should exceed 0.5 .

The Cronbach's alpha scores ranged from 0.83 to 0.96 (Table 2). This indicated that each construct exhibited strong internal reliability. A generally acceptable low limit is 0.7 (Hair et 
al., 1998).

All of the standard factor-loading values in the confirmatory factor analysis of the measurement model exceeded 0.5 , and were significant at $\mathrm{p}=0.01$. The composite reliabilities of the constructs ranged from 0.88 to 0.97 , and the AVE ranged from 0.58 to 0.93 . Therefore, all the aforementioned criteria for convergent validity were met.

Furthermore, a rule for assessing discriminant validity requires that the square root of the AVE should be larger than the correlations between the construct and any other one in the model (Chin, 1998b). All constructs met this requirement (Table 3).

$<<$ Table 2 and 3 here $>>$

\subsection{Analysis of Common Method Variance (CMV)}

Common Method Variance (CMV) may arise when conducting research with a single instrument, particularly self-reported measures (Malhotra et al., 2006; Meade et al., 2007). CMV leads to spurious relationships between measures, and thus threatens the validity of the conclusions in research studies (Podsakoff et al., 2003). As the data collected in this study was self-reported and based on the same survey instrument, the potential appearance of CMV was a concern.

Craighead et al. (2011) suggested that Harman's single-factor test is straightforward for CMV without incurring additional resources. The test is performed by including all the survey items in an exploratory analysis. CMV would be present if a single factor emerges from the factor analysis, or a factor accounts for a substantial amount of variance (Podsakoff and Organ, 1986). The threat of common method bias is considered to be high if a single factor accounts for more than 50\% of variance (Harman, 1976; Messerschmidt and Hinz, 2012). In this study, Harman's single-factor test was performed, and no significant CMV was found (Appendix B).

Ylitalo (2009) mentioned that the techniques for controlling CMV in covariance-based structural equation modelling (CBSEM) are not always applicable to PLS because of the differences in model estimation. An approach for assessing CMV in studies applying PLS (e.g. Pavlou et al., 2007; Dong et al., 2009; Rönkkö and Ylitalo, 2011) was followed and employed. A proxy for CMV was formed by conducting a factor analysis for all of the

measurement items. It was included in the model of this study as a predictor for the endogenous construct, behavioural intention. The first emerging factor is the proxy because it 
is "best approximation of CMV" (Podsakoff et al. 2003, p. 893). All the significant relationships remained unchanged, and the proxy only increased the variance explained in the endogenous construct by $2.4 \%$. This indicated that CMV did not cause any problems in this study.

\subsection{Structural Model}

The structural model was evaluated by examining the structural paths, t-statistics, and variance explained (i.e., $\mathrm{R}^{2}$ value). Path significances were determined by running the model using a bootstrap resampling routine with 198 cases and 1,000 samples. Hypothesis tests were carried out to test the study's proposed model.

Results of the analysis are presented in Figure 2.

$<<$ Figure 2 here $>>$

The $\mathrm{R}^{2}$ value of behavioural intention (0.839) shows the substantial amount of variance in recycling intention that can be explained by attitude, subjective norms, PBC, moral norms, awareness of consequences, and perceived policy effectiveness. Hair et al. (2011) proposed that the $\mathrm{R}^{2}$ values of $0.25,0.50$, and 0.75 in a structural model of PLS could be interpreted as weak, moderate, and substantial, respectively. The value of 0.839 indicates that the model explains a substantial amount of the variance in recycling intention. All paths were significant at $\mathrm{p}<0.05$, except for the correlation between attitude and recycling intention (H1).

The results shown in Table 4 support hypotheses 2 to 8 :

- The path from SUBN to INT was significant, with a level effect size and low predictive relevance $\left(\beta=0.14, t=2.76, p<0.01, f^{2}=0.06, q^{2}=0.03\right)$.

- The path from PBC to INT was significant with a medium effect size and relatively higher, albeit still low, predictive relevance $\left(\beta=0.34, t=5.62, p<0.01, f^{2}=0.21, q^{2}=\right.$ $0.13)$.

- What is more, the MORN significantly correlated with INT, with a low effect size and low predictive relevance $\left(\beta=0.28, t=3.36, p<0.01, f^{2}=0.11, q^{2}=0.05\right)$.

- The coefficient of the path from CONS to INT was significant, with a low effect size and low predictive relevance $\left(\beta=0.10, t=2.13, p<0.05, f^{2}=0.02, q^{2}=0.01\right)$.

- The path from POLICY to INT $\left(\beta=0.22, t=4.69, p<0.01, f^{2}=0.13, q^{2}=0.07\right)$ was also significant, with low to medium effect size and low predictive relevance.

- Finally, the two paths INT to DBEV and INT to IBEV were also significant. 
$<<$ Table 4 here $>>$

The $\mathrm{R}^{2}$ value of 0.839 can be divided in terms of multiple regression coefficients, the correlations between the dependent variables, and the explanatory ones (Tenenhaus et al., 2005; Table 5). This allows for an understanding of the contribution of each explanatory variable to predictions regarding the dependent variables.

For this model, PBC, followed by MORN, were the most important variables in the prediction of INT, contributing $33.99 \%$ and $28.30 \%$ to the $\mathrm{R}^{2}$ respectively. In addition, POLICY, SUBN, and CONS contributed $19.39 \%, 12.27 \%$, and $8.18 \%$ to the $\mathrm{R}^{2}$, respectively. This illustrates that the newly proposed construct, namely perceived policy effectiveness, contributed significantly to explaining recycling intentions.

$<<$ Table 5 here $>>$

Unlike covariance-based structural equation modelling, PLS does not provide various methods for the validation of models, such as $\chi^{2}$ and other related measures (Henseler and Sarstedt, 2013). However, the criterion goodness of fit (GoF) for PLS was proposed by Tenenhaus et al. (2004). GoF is defined as small (0.10), medium (0.25), and large (0.36) (Latan and Ghozali, 2012; Terzi and Economides, 2011). The model in this study had a GoF value of 0.73 , meaning the model was quite acceptable.

\subsection{Perceived Policy Effectiveness}

The newly proposed construct, POLICY, contributed $19.39 \%$ in explaining recycling intentions, and Appendix A shows the reported level of perceived policy effectiveness and the descriptive statistics of the other constructs within the sample.

Among the ten indicators of POLICY, respondents favourably rated the Government's promotion efforts, i.e. indicators 3,5 , and 7 , with means ranging from 4.17 to 4.39 . This shows a higher level of perceived effectiveness in these policy measures. Nevertheless, the sufficiency of recycling guidelines, facilities, and recycling facilitation, i.e. indicators 2,4 , and 9 , was rated comparatively low with means ranging from 3.39 to 3.47 .

\section{Discussion}

The TPB laid a useful foundation for explaining recycling behaviour. Among the three variables, subjective norms and $\mathrm{PBC}$ were significantly correlated with behavioural intention. 
This finding is consistent with those empirical studies in related areas, such as Oom Do Valle et al. (2005) and Cheung et al. (1999). On the contrary, the variable attitude was not statistically correlated with behavioural intention. This is consistent with the studies of Sidique et al. (2010) and Chen and Tung (2010) (but not other previous studies, e.g. Kelly et al., 2006; Oskamp et al., 1991; Tonglet et al., 2004). It is because additional constructs to TPB, moral norms, awareness of consequences, and perceived policy effectiveness, took over the predictive power from attitudes. A PLS analysis was performed with the three key variables of the TPB, and the results showed that attitude was a significant predictor of recycling intentions $(\beta=0.28, t=3.01)$.

The additional variables, i.e. moral norms and awareness of consequences, included in the model were also statistically significant in explaining the behavioural intention of recycling behaviour. Moral norms were significant predictors in the studies by Chen and Tung (2010) and Oom Do Valle et al. (2005), while the current study's result vis-à-vis awareness of consequences agreed with the findings by Tonglet et al. (2004).

\subsection{Implications of Study Results}

The results suggest that $\mathrm{PBC}$ and moral norms are the most important variables in behavioural intention as they contributed $33.99 \%$ and $28.30 \%$ to the $\mathrm{R}^{2}$, respectively. Perceived policy effectiveness also contributed approximately $20 \%$ to the $\mathrm{R}^{2}$ in explaining behavioural intention. However, the contributions of the other two variables, subjective norms (12.27\%) and awareness of consequences (8.18\%), were comparatively low.

The major considerations for policy makers about the design and implementation of recycling schemes can be inferred from these results:

- Enhancing the knowledge and understanding of recycling, and its environmental impacts, to heighten the $\mathrm{PBC}$ of individuals. For example, using a promotional programme to illustrate where people can find recycling facilities, and how recyclables should be sorted, stored, and handled, etc.

- Promoting the significance of recycling and portraying recycling as a socially desirable behaviour and trend that is not only environmental friendly but also a moral obligation of citizens. This can strengthen an individual's perception of recycling as a moral norm.

When people hold a more positive perception of policy effectiveness, they will also engage in recycling behaviour. As stated by Steg and Vlek (2009) and Wan and Shen (2013), informational strategies such as promotional campaigns can be implemented to enhance people's perception of the policy's effectiveness. They can accent what the Government has 
been doing to facilitate and encourage recycling, what accomplishments have been achieved so far, and the subsequent positive impacts on the environment. The perceived effectiveness would be enhanced through them.

Promotion-related indicators were perceived to be more effective than facilitation-related ones, as revealed by the descriptive statistics of the ten indicators of perceived policy effectiveness. This implied that people were satisfied with the clarity of promotional messages. Nevertheless, the facilitation of recycling was less satisfactory in terms of the provision of guidelines and waste separation bins. The Government should offer more recycling bins and publish concise guidance through various media, such that people develop a higher level of perceived effectiveness of facilitation-related measures.

In this study, the relationship between perceived policy effectiveness and behavioural intention is a novel finding. This highlights a major issue for future research in the area of recycling and pro-environmental behaviour.

\subsection{Limitations and Future Research}

This study possessed several limitations that should be addressed in future research.

1. The policy measures on waste reduction and recycling in Hong Kong are features of a unique culture, and the findings pertaining to them may or may not be generalised in other areas and contexts. Therefore, further research is needed to apply the model in different settings and with different groups.

2. Since all measures were based on self-reporting, social desirability bias may exist in the results. Craighead et al. (2011) suggested that the post hoc statistical technique, Harman's single-factor test, may not be fully reliable, particularly in detecting small levels of CMV. On the contrary, there is the possibility that the first factor accounts more than $50 \%$ of the variance where CMV does not exist (Ylitalo, 2009). A previously defined "marker variable", an additional variable that is theoretically unrelated to the study variables, could be included in the survey instrument; the common method variance could subsequently be evaluated based on the correlation between the marker variable and study variables (Lindell and Whitney, 2001; Rönkkö and Ylitalo, 2011).

3. The younger groups aged 20-24 and 25-29 were over-represented in the sample of the street survey conducted in this study. Further research is necessary to apply the model in different settings and with different groups. 
4. Policy measures are considered a single construct in this study. Future research may be needed to investigate the correlations between each category of the policy tools and recycling intentions. In this way, the extent of each policy tool influencing recycling intentions can be investigated.

5. The $\mathrm{R}^{2}$ values of direct and indirect behaviour were 0.766 and 0.371 , respectively; the amount of variance explained by indirect behaviour was comparatively low. In the study by Tobler et al. (2012) on climate change, policy support was influenced by political affiliation, attitude of concern, and perceived costs and benefits. These factors could be included in future studies.

6. Normative considerations are not influential in high-cost situations (e.g. travel mode choice), and they play a less important role than other factors (e.g. costs and convenience) (Diekmann and Preisendörfer, 2003). Hansmann et al. (2006) found that when social norms were widely shared within and internalised by the society, the predictive power of personal norms and attitudes was reduced. It was suggested that normative considerations be deactivated in explaining individual behaviours. Future research can be used to look into these issues concerning model development.

\section{Conclusions}

This study extended the TPB model to explain the relationship between perceived policy effectiveness and recycling behaviour in Hong Kong. The results showed the following:

- Recycling intention is influenced by subjective norms, perceived behavioural control, moral norms, awareness of consequences, and perceived policy effectiveness of the Government.

- Recycling behaviour (direct behaviour) and support for policy measures (indirect behaviour) are influenced by recycling intention.

- Promotional measures were perceived as being more effective than the provision of recycling facilities and guidelines.

The study filled the research gap to investigate the role of perceived effectiveness of policy measures in predicting recycling behaviour. It concluded that the Government should provide more recycling bins and guidelines on recycling activities. It proposed informational strategies to enhance people's perception of policy effectiveness, i.e. to highlight the activities and accomplishments that have been achieved by the public authority. 


\section{References}

Ajzen, I. (1991). The theory of planned behaviour. Organizational Behaviour and Human Decision Processes, 50, 170-211.

Ajzen, I., \& Fishbein, M. (1980). Understanding attitude and predicting social behaviour. Englewood Cliffs, NJ: Prentice Hall.

Armitage, C. J., \& Conner, M. (2001). Efficacy of the theory of planned behaviour: A meta-analytic review. British Journal of Social Psychology, 40, 471-499.

Beck, L., \& Ajzen, I. (1991). Predicting dishonest actions using the theory of planned behaviour. Journal of Research in Personality, 25(3), 285-301.

Bratt, C. (1999). The impact of norms and assumed consequences on recycling behavior. Environment and behavior, 31(5), 630-656.

Census and Statistics Department. (2011). 2011 Population Profile. Retrieved from http://www.census2011.gov.hk/.

Chen, M. F., \& Tung, P. J. (2010). The moderating effect of perceived lack of facilities on consumers' recycling intentions. Environment and Behaviour, 42(6), 824-844.

Cheung, S. F., Chan, D. K. S., \& Wong, Z. S. Y. (1999). Reexamining the theory of planned behaviour in understanding wastepaper recycling. Environment and Behaviour, 31, 587-611.

Chin, W. W. (1998a). Issues and opinion on structural equation modeling. MIS Quarterly, 22(1), 7-16.

Chin, W. W. (1998b). The partial least squares approach for structural equation modeling. In G. A. Marcoulides (Ed.), Modern methods for business research (pp. 295-336). Mahwah, NJ: Erlbaum.

Chung, S. S. (2010). Projecting municipal solid waste: The case of Hong Kong SAR. Resources, Conservation and Recycling, 54, 759-768.

Craighead, C. W., Ketchen, D. J., Dunn, K. S., \& Hult, G. G. (2011). Addressing common method variance: guidelines for survey research on information technology, operations, and supply chain management. Engineering Management, IEEE Transactions on, 58(3), 578-588.

Davies, J., Foxall, G. R., \& Pallister, J. (2002). Beyond the intention-behaviour mythology: an integrated model of recycling. Market Theory, 2(1), 29-113.

Diekmann, A., \& Preisendörfer, P. (2003). Green and Greenback The Behavioral Effects of Environmental Attitudes in Low-Cost and High-Cost Situations. Rationality and Society, $15(4), 441-472$.

Dong, S., Xu, S. X., \& Zhu, K. X. (2009). Research Note-Information Technology in Supply Chains: The Value of IT-Enabled Resources Under Competition. Information 
Systems Research, 20(1), 18-32.

Elmore, R. F. (1987). Instruments and strategy in public policy. Review of Policy Research, 7(1), 174-186.

Environment Bureau. (2013). Hong Kong: Blueprint for Sustainable Use of Resources 2013-2022. Retrieved from: http://www.enb.gov.hk/en/files/WastePlan-E.pdf.

Environmental Protection Department. (2005). A policy framework for the management of municipal solid waste, 2005-2014. Retrieved from http://www.epd.gov.hk/epd/msw/index.html.

Environmental Protection Department. (2010). An overview on challenges for waste reduction and management in Hong Kong. Retrieved from http://www.epd.gov.hk/epd/english/environmentinhk/waste/waste_maincontent.html.

Fishbein, M., \& Ajzen, I. (1975). Belief, attitude, intention, and behaviour: An introduction to theory and research. Reading, MA: Addison-Wesley.

Fornell, C., \& Larcker, D. F. (1981). Evaluating structural equation models with unobservable variables and measurement error. Journal of Marketing Research, 18(1), 39-47.

Gefen, D., Straub, D. W., \& Boudreau, M. C. (2000). Structural equation modeling and regression: Guidelines for research practice. Communications of the Association for Information System, 4(7), 1-79.

Godin, G., Valois, P., Lepage, L., \& Desharnais, R. (1992). Predictors of smoking behaviour: An application of Ajzen's theory of planned behaviour. British Journal of Addiction, 87(9), 1335-1343.

Gormley, W. (1987). Bureau-Bashing: A framework for analysis. In meetings of the American Political Science Association, Chicago, IL.

Hair, J. F., Anderson, R. E., Tatham, R. L., \& Black, W. C. (1998). Multivariate data analysis, 5th ed, Upper Saddle River: Prentice Hall.

Hair, J. F., Ringle, C. M., \& Sarstedt, M. (2011). PLS-SEM: Indeed a silver bullet. The Journal of Marketing Theory and Practice, 19(2), 139-152.

Hansmann, R., Bernasconi, P., Smieszek, T., Loukopoulos, P., \& Scholz, R. W. (2006). Justifications and self-organization as determinants of recycling behavior: The case of used batteries. Resources, Conservation and Recycling, 47(2), 133-159.

Harman, H. H. (1976). Modern factor analysis (3rd ed.). Chicago, IL: University of Chicago Press.

Heath, Y., \& Gifford, R. (2002). Extending the theory of planned behaviour: Predicting the use of public transportation. Journal of Applied Social Psychology, 32(10), 2154-2189.

Henseler, J., Sarstedt, M. (2013). Goodness-of-fit indices for partial least squares path modelling. Computational Statistics, 28(2), 565-580.

Hood, C. (1986). The tools of government. Chatham, NJ: Chatham House.

Hopper, J., \& Nielsen, J. M. (1991). Recycling as altruistic behaviour: normative and 
behavioural strategies to expand participation in a community recycling program. Environment and Behaviour, 23, 195-220.

Information Services Department. (2010). Press release - LCQ18: The number and locations of 3-coloured waste separation bins. Retrieved from http://www.info.gov.hk/gia/general/201005/26/P201005260108.htm.

Information Services Department. (2012). Press release - LCQ20: Crowd control in MTR stations. $\quad$ Retrieved from http://www.info.gov.hk/gia/general/201205/09/P201205090211.htm.

Information Services Department. (2013). Press release - LCQ19: Three-colour waste separation bins. Retrieved from http://www.info.gov.hk/gia/general/201302/27/P201302270298.htm.

Jöreskog, K. G. (1989). LISREL 7: A guide to the program and applications. Chicago: SPSS.

Jöreskog, K. G., \& Wold, H. (1982). The ML and PLS techniques for modeling with latent variables: Historical and comparative aspects. In K. G. Jöreskog, \& H. Wold (Eds.), Systems under indirect observation: Causality, structure and prediction (pp. 219-243). Amsterdam: North Holland.

Kaiser, F. G., Doka, G., Hofstetter, P., \& Ranney, M. A. (2003). Ecological behavior and its environmental consequences: A life cycle assessment of a self-report measure. Journal of Environmental Psychology, 23(1), 11-20.

Kelly, T. C., Mason, I. G., \& Leiss, M. W. (2006). University community responses to on-campus resources recycling. Resources Conservation and Recycling, 47, 42-55.

Latan, H., and Ghozali, I. (2012). Partial Least Squares: Concept and Application Path Modeling using program XLSTAT-PLS for Empirical Research, BP UNDIP.

Legislative Council. (2013). Discussion papers for Public Works Subcommittee Meeting: Southeast New Territories Landfill Extension, Northeast New Territories Landfill Extension, and West New Territories Landfill Extension.

Lindell, M. K., \& Whitney, D. J. (2001). Accounting for common method variance in cross-sectional research designs. Journal of applied psychology, 86(1), 114.

Liska, A. E. (1984). A critical examination of the causal structure of the Fishbein/Ajzen attitude-behavior model. Social Psychology Quarterly, 61-74.

Malhotra, N. K., Kim, S. S., \& Patil, A. (2006). Common method variance in IS research: A comparison of alternative approaches and a reanalysis of past research. Management Science, 52(12), 1865-1883.

Mathieson, K. (1991). Predicting user intentions: comparing the technology acceptance model with the theory of planned behaviour. Information Systems Research, 2(3), $173-191$.

Meade, A. W., Watson, A. M., \& Kroustalis, C. M. (2007). Assessing common methods bias in organizational research. In 22nd annual meeting of the society for industrial and 
organizational psychology, New York, 1-10.

Messerschmidt, C. M., \& Hinz, O. (2012). Explaining the adoption of grid computing: An integrated institutional theory and organizational capability approach. The Journal of Strategic Information Systems, 22(2), 137-156.

Oom Do Valle, P., Rebelo, E., Reis, E., \& Menezes, J. (2005). Combining behavioural theories to predict recycling involvement. Environment and Behaviour, 37(3), 364-396.

Oskamp, S., Harrington, M. J., Edwards, T. C., Sherwood D. L., Okuda S. M., \& Swanson, D. C. (1991). Factors influencing household recycling behaviour. Environment and Behaviour, 23, 494-519.

Parker, D., Manstead, A. S. R., Stradling, S. G., Reason, J. T., \& Baxter, J. S. (1992). Intention to commit driving violations: An application of the theory of planned behaviour. Journal of Applied Psychology, 77(1), 94-101.

Pavlou, P. A., Liang, H., \& Xue, Y. (2007). Understanding and mitigating uncertainty in online exchange relationships: A principal-agent perspective. MIS quarterly, 31(1), 105-136.

Podsakoff, P. M., \& Organ, D. W. (1986). Self-reports in organizational research: Problems and prospects. Journal of Management, 12(4), 531-544.

Podsakoff, P. M., MacKenzie, S. B., Lee, J. Y., \& Podsakoff, N. P. (2003). Common method biases in behavioral research: a critical review of the literature and recommended remedies. Journal of Applied Psychology, 88(5), 879.

Ringle, C.M., Wende, S., Will, S. (2005). SmartPLS 2.0 (M3) Beta, Hamburg, http://www.smartpls.de.

Rönkkö, M., \& Ylitalo, J. (2011). PLS marker variable approach to diagnosing and controlling for method variance. ICIS 2011 Proceedings. Paper 8.

Schneider, A., Ingram, H. (1990). Behavioural Assumptions of Policy Tools. The Journal of Politics, 52(2), 510-529.

Schwartz, S. H. (1977). Normative influences on altruism. In L. Berkowitz (Ed.), Advances in experimental social psychology (pp. 221-279). New York: Academic Press.

Sidique, S. F., Lupi, F., \& Joshi, S. V. (2010). The effects of behaviour and attitude on drop-off recycling activities. Resources, Conservation and Recycling, 54, 163-170.

Sing Tao Daily. (2013). Insufficient provision of waste separation bins. Retrieved from http://www.singtao.com.hk/yesterday/loc/0502ao08.html. [in Chinese].

Steg, L., Dreijerink, L., \& Abrahamse,W. (2005). Factors influencing the acceptability of energy policies: testing VBN theory. Journal of Environmental Psychology, 25(4), 415-425.

Steg, L., Dreijerink, L., Abrahamse, W. (2006). Why are energy policies acceptable and effective? Environment and Behaviour, 38(1), 92-111.

Steg, L., Vlek, C. (2009). Encouraging pro-environmental behaviour: An integrative review 
and research agenda. Journal of Environmental Psychology, 29(3), 309-317.

Stern, P. C., Dietz, T., \& Black, J. S. (1985). Support for environmental protection: The role of moral norms. Population and Environment, 8(3-4), 204-222.

Tenenhaus, M., Esposito Vinzi, V., Chatelin, Y.-M., \& Lauro, C. (2005). PLS path modeling. Computational Statistics \& Data Analysis, 48(1), 159-205.

Thøgersen, J. (1996). Recycling and Morality A Critical Review of the Literature. Environment and Behavior, 28(4), 536-558.

Tobler, C., Visschers, V., Siegrist, M. (2012). Addressing climate change: Determinants of consumers' willingness to act and to support policy measures. Journal of Environmental Psychology, 32(3), 197-207.

Tonglet, M., Phillips, P. S., \& Read, A. D. (2004). Using the Theory of Planned Behaviour to investigate the determinants of recycling behaviour: a case study from Brixworth, UK. Resources, Conservation and Recycling, 41(3), 191-214.

Vedung, E. (1998). Policy instruments: typologies and theories. In: Bemelmans-Videc, M., Rist, R.C., Vedung, E. (Eds.), Carrots, Sticks \& Sermons: Policy Instruments \& Their Evaluation. Transaction Publishers, New Brunswick, NJ, pp. 21-58.

Vining, J., \& Ebreo, A. (1992). Predicting Recycling Behavior from Global and Specific Environmental Attitudes and Changes in Recycling Opportunities1. Journal of Applied Social Psychology, 22(20), 1580-1607.

Wan, C., Cheung R., Shen, G. (2012). Recycling attitude and behaviour in university campus: a case study in Hong Kong. Facilities, 30(13/14), 630-646.

Wan, C., Shen, G. (2013). Perceived policy effectiveness and recycling behaviour: The missing link. Waste Management, 33(4), 783-784.

Yiu, C.Y., Xu, S. (2012). A tenant-mix model for shopping malls. European Journal of Marketing, 46(3), 524-54.

Ylitalo, J. (2009). Controlling for common method variance with partial least squares path modeling: A Monte Carlo study. Technical paper, Helsinki University of Technology. 